1 Sheridan MP. Assessing fitness to drive in dementia and other psychiatric conditions: a higher training learning opportunity at a driving assessment centre. Psychiatrist 2012; 36: 113-6.

2 Driver and Vehicle Licensing Agency. At a Glance Guide to the Current Medical Standards of Fitness to Drive (For Medical Practitioners). DVLA, 2012 (http://www.dft.gov.uk/dvla/medical/ataglance.aspx).

3 NHS East Midlands. An Independent Investigation into the Care and Treatment of a Person Using the Services of Leicestershire Partnership NHS Trust (Ref. 2007/197). East Midlands Strategic Health Authority, 2010.

4 General Medical Council. Confidentiality: Reporting Concerns about Patients to the DVLA or the DVA (Supplementary Guidance). GMC, 2009 (http://www.gmc-uk.org/Confidentiality_reporting_concerns_DVLA_ 2009.pdf_27494214.pdf).

Febronie Nkunzimana, registrar (CT1), Tees, Esk and Wear Valleys NHS Foundation Trust, Northern Deanery, email: fnkunzimana@ doctors.org.uk; Mukesh Kripalani, consultant psychiatrist, Tees, Esk and Wear Valleys NHS Foundation Trust, Northern Deanery.

doi: $10.1192 / p b .36 .7 .272 a$

\section{Anecdote about Denis}

May I please add a personal note to your obituary of Dr Denis Murphy? ${ }^{1}$ Denis returned to Britain at about the same time as I returned from Australia. Before our eventual careers took shape, we tended to follow each other around south London experiencing what Denis often referred to as 'A plague of locums', and became friends.

A biological psychiatrist in those days, his attachment to general medicine was keen, as shown by an incident in Dublin one night when I happened to be visiting. We had taken his mother to a fine performance of Wilde's A Woman of No Importance. It was dark and raining on the return to Terenure when we encountered a policeman directing traffic around a badly injured motorcyclist. Denis stopped the car and insisted on offering his (and my) services. There followed, for an inordinate length of time before the ambulance finally arrived, the improbable scene of two sodden psychiatrists attempting mouth-to-mouth CPR on an all-but-moribund youth as cars went by, perilously close, either side.

Typically, wanting to know the outcome of our efforts, Denis rang the hospital the following day. The accident victim was deep in a coma and not expected to recover. Putting down the receiver, my friend remarked, philosophical as ever, 'At least we saved his kidneys for somebody!'

I shall long remember the near-mischievous twinkle in his eye, and the perfectly expressive, wry, lopsided grin, which accompanied this observation. They captured the very essence of his charm.

1 Hollis P. Dr Denis Murphy. Psychiatrist 2012; 36: 198.

Larry Culliford, retired psychiatrist and author, West Sussex, email: auud26@dsl.pipex.com.

doi: $10.1192 / p b .36 .7 .273$

\section{Competition and choice}

Sugarman's commentary ${ }^{1}$ strikes me as rather missing the point. I did not take Mynors-Wallis ${ }^{2}$ to be criticising practitioners working outside of the National Health Service, but instead to be looking critically at the evidence that competition is the best mechanism for improving care. Sugarman makes much of the value of patient choice in improving services, although does not cite any evidence in favour of this assertion. In many mental health settings, this is also disingenuous. Our patients do not have any choice, instead it is the primary care trusts (PCTs) who make choices on their behalf. Even with the most benign possible view of these arrangements it is hard to believe that PCTs make their decisions on the basis of the wishes of the patients or their families as their primary concern. It may be that PCTs are, in fact, fantastically good at choosing the best, highest-quality, and most cost-efficient healthcare, but let us not pretend it is about patient choice.

1 Sugarman P. Diversity and choice in mental healthcare. Commentary on . Cooperation or competition? Psychiatrist 2011; 35: 443-4.

2 Mynors-Wallis L. Cooperation or competition? Proposed changes in healthcare provision in England. Psychiatrist 2011; 35: 441-3.

Simon P. Wilson, Consultant Forensic Psychiatrist, Oxleas NHS Foundation Trust, email: simon.wilson@kcl.ac.uk

doi: $10.1192 / p b .36 .7 .273 a$

\section{Royal College examination fees surplus}

At the current level of membership examination fees at the Royal College of Psychiatrists, a resident in psychiatry who passes every part first time pays a total of $E 2136 .^{1}$ These costs are intended to cover only expenses rather than to generate profit, a message which many of us have accepted and disseminated. ${ }^{2}$ We were therefore disappointed to learn recently that in 2010-2011, the College made a profit of approximately $€ 1.5$ million from exam fees. Some residents are understandably asking for candidates to receive a refund, a process for which there is historical precedent. ${ }^{3}$

We have another suggestion for how this money could be put to good use for the benefit of residents, the College and psychiatry as a whole. The College's annual International Congress currently receives about $€ 70000$ from pharmaceutical companies and other organisations in return for exhibition space (personal communication with the College's Conference Office). Such relationships are undesirable because drug company information affects prescribing. ${ }^{4}$ Most doctors do acknowledge this to be true of their colleagues, although the majority believe they are themselves, of course, unaffected. ${ }^{5}$ Further, and particularly pertinent to psychiatry, is the effect that drug company relationships may have on our patients' confidence in our treatment recommendations. Many detained patients are suspicious that psychiatrists' prescribing is motivated by connections with the pharmaceutical industry rather than a genuine intention to improve mental health. We acknowledge the College's considerable progress in the right direction over the issue, but it is problematic to deny such allegations while promotional materials continue to be welcome at our annual congress.

If the surplus from examination fees were used to subsidise the International Congress, it would be possible to have no commercial exhibitor fees for at least 10 years, by which time alternative arrangements could be made. Furthermore, some of the surplus could be 'given back' in the form of bursaries for residents to attend the conference. This course of action would allow the College to lead by positive example, while providing wider benefits for UK psychiatrists and our patients.

1 MRCPsych Examinations Calendar 2012: http//www.rcpsych.ac.uk/ pdf/MRCPsych\%20Examinations $\% 20$ Calendar\%202012\%20 130212.pdf 